\title{
THE PHONOLOGY OF YUROK GLOTTALIZED SONORANTS: SEGMENTAL FISSION UNDER SYLLABIFICATION ${ }^{1}$
}

\author{
Juliette Blevins
}

\author{
UNIVERSITY OF CALIFORNIA, BERKELEY
}

\begin{abstract}
Yurok, an endangered Algic language of northwest California, has a series of glottalized sonorants which contrast with plain nonglottalized sonorants. Glottalized sonorants have interesting phonological properties which distinguish them from other segment types in Yurok, including a restriction to postvocalic environments and fission under syllabification. In this paper, I analyze sound patterns involving Yurok glottalized sonorants and discuss their implications for phonological theory.
\end{abstract}

[KEYWORDS: Yurok, phonology, glottalized sonorants, syllabification]

1. Introduction. Yurok, an Algic language of northwestern California, has a series of glottalized sonorants which contrast with their plain nonglottalized counterparts. Glottalized sonorants show distinct distributions from other segment types. Though there is good evidence that they are single segments, in intervocalic position they are syllabified as clusters, with glottal stop closing one syllable and a sonorant opening the next. In this study, I describe the distribution of glottalized sonorants and suggest that segmental fission under syllabification is the result of word-based syllabification algorithms which are based on surface associations between word and syllable edges.

The primary published data sources for this study are Kroeber (1911), Waterman (1920), Spott and Kroeber (1942), Robins (1958) $=[R]$, Berman $(1982 a)=[\mathrm{B}]$, Sapir (2001), and Exline (n.d.). The primary unpublished data for this work comes from my 2001-2003 fieldwork with the six speakers mentioned in footnote 1 . These data consist primarily of elicitations but also include spontaneous speech and short narratives; in many cases, the same forms were confirmed by two or three different speakers, and also occur in published sources.

In 2, I introduce the segment inventory of Yurok and surface contrasts in plain versus glottalized sonorants. Section 3 illustrates a range of alterna-

${ }^{1}$ This work was partly supported by National Science Foundation grant BCS-0004081 to the University of California, Berkeley. Sincere thanks to Aileen Figueroa, Jimmie James, Glen Moore, Archie Thompson, Georgiana Trull, and Jesse Van Pelt for sharing their knowledge of Yurok with me, and to the Yurok Language Committee of the Yurok Tribe for their general support. An early version of this paper was presented at the Fiftieth Anniversary Conference of the Survey of California and Other Indian Languages, June 2002, University of California, Berkeley, and a later version at the Department of Linguistics, University of Hawaii, Manoa, in April 2003. I am grateful to Howard Berman and Andrew Garrett for comments and corrections on earlier drafts.

[IJAL, vol. 69, no. 4, October 2003, pp. 371-96]

(C) 2003 by The University of Chicago. All rights reserved.

0020-7071/2003/6904-0003\$10.00 
tions involving glottalized sonorants, while $\mathbf{4}$ summarizes arguments for the segmental status of these same segments. Section $\mathbf{5}$ presents evidence that, despite their monosegmental status, glottalized sonorants function as clusters intervocalically in syllabification. An analysis of segmental fission is presented in the context of general models of surface word-based syllabifications. Fission occurs in compliance with surface constraints on word-edge phonotactics: in Yurok, all words begin with consonants and word-initial glottalized sonorants are prohibited. The analysis is followed by a brief summary in $\mathbf{6}$.

2. Yurok glottalized sonorants. The Yurok segment inventory is shown in (1).

(1) Yurok segment inventory

Consonants and Glides

\begin{tabular}{|c|c|c|c|c|}
\hline Voiceless stops/affricates & $p$ & $t$ & $t \int$ & $k$ \\
\hline Ejectives & $p^{\prime}$ & $t^{\prime}$ & $t \rho^{\prime}$ & $k^{\prime}$ \\
\hline Voiceless fricatives & & $s[\mathrm{~s}], t$ & $\int$ & $x$ \\
\hline Plain nasals & $m$ & $n$ & & \\
\hline Glottalized nasals & 'm & 'n & & \\
\hline Plain liquids \& glides & $w$ & $l, r[\imath]$ & $y[\mathrm{j}]$ & $\gamma$ \\
\hline Glottalized liquids \& glides & ’w & ' $l, ' r$ & $y\left[{ }^{\prime} \mathrm{j}\right]$, & ' $\gamma$ \\
\hline
\end{tabular}

Laryngeals

$h, ?$

Vowels

$\begin{array}{lll}i, i: & & u, u: \\ e & r[\curvearrowright], r: & o, o: \\ & a, a: & \end{array}$

Symbols have their approximate IPA values, with the following exceptions: $y=[\mathrm{j}], r=[$.$] (nonsyllabic in the margin, syllabic in the nucleus), and the$ voiced velar $\gamma$ has very little fricative noise, behaving in most respects like a sonorant consonant. ${ }^{2}$

Yurok glottalized sonorants are phonetically preglottalized. Glottalization may be realized as creak on a preceding vowel, as a glottal stop intervening between a preceding vowel and a following sonorant, or as a combination of

\footnotetext{
${ }^{2}$ Symbols here are the same as Robins (1958) and Berman (1982a), with the following exceptions: Robins's $i \cdot u \cdot, o \cdot a \cdot$ are written as $i: u:, o:, a:$; Robins's $\iota, \iota$ are written as $r, r$; Robins's $\check{s}, t$ are written as $\int, t ; c, c$ ' are written as $t \int, t \int$ '; and $g$ is written as $\gamma$. The rhotic vowels $r, r$ : are variants of /a, e, o/, /a:, o:/ under rhotic harmony, and are clearly of recent origin. High vowels /i, i:, u, u:/ do not undergo rhotic harmony but are transparent to it. Surface forms are enclosed in square brackets and nonsurface forms in virgules.

Phonetic values associated with vowels are highly variable, especially for short unstressed vowels. Where direct reference is made to stress, stress is marked by an acute accent over the stressed vowel. For a preliminary account of nominal stress, see Blevins (2003a).
} 
these two properties. In word-final position, the sonorant portion of a preglottalized sonorant is often devoiced.

Minimal and near-minimal pairs showing the plain vs. glottalized sonorant contrast are given in (2), with segments for comparison in boldface. ${ }^{3}$

(2) Underlying and surface contrasts between plain and glottalized sonorants

\begin{tabular}{|c|c|c|c|c|c|c|}
\hline & Stem-init & & Medial & & Final & \\
\hline Plain & k'e-wen & 'your woman/sF' & kewoy & 'burden basket' & mew & 'widower' \\
\hline Glottalized & k'e-'wes & 'your body/sF' & ke'win & 'eel' & $m e^{\prime} \boldsymbol{w}$ & $\begin{array}{l}\text { 'come } \\
\text { from/UI' }\end{array}$ \\
\hline Plain & k'e-yah & 'your stomach' & keyoh & 'Autumn' & k'e-mey & 'your tears' \\
\hline Glottalized & k'e-'yotf & 'your boat' & ke'yolew & ‘spit/UI’ & $k^{\prime} e-m e^{\prime} y$ & $\begin{array}{l}\text { 'your } \\
\text { daughter' }\end{array}$ \\
\hline Plain & k'e-mol & 'your head' & koma & 'hard, still' [R] & kem & 'again' \\
\hline Glottalized & k'e-'mo: & $\begin{array}{l}\text { 'your married } \\
\text { daughter' }[R]\end{array}$ & ko'mi & 'excessively’ [R] & $k e ' \boldsymbol{m}$ & 'food/sF' \\
\hline Plain & k'e-rep & 'your sugar/sF' & no:rew & 'pretty' & heyor & 'month' \\
\hline Glottalized & k'e-'rep & 'your eyebrow' & no:'repek' & 'I follow' & ra:yo'r $r$ & 'run past/ui' \\
\hline Plain & k'e-lew & 'your net/sF' & tolowehl & 'Tolowa' & $k^{\prime} e-t \int e l$ & 'your ribs' \\
\hline Glottalized & k'e-'lep & 'your hair/sF' & 'o'lomah & 'come in!' & $k e^{\prime} l$ & 'you (sg.)' \\
\hline Plain & & & teno: & 'to be much/uI' & tfin & $\begin{array}{l}\text { 'young } \\
\mathrm{man} / \mathrm{sF}\end{array}$ \\
\hline Glottalized & & & te'noy't & 'there is a big fire' & $t f i$ 'n & 'early' \\
\hline
\end{tabular}

Morpheme-initial /'n/ and /' $\mathrm{m} /$ are found in very few lexemes, though one of these, the first-person pronominal prefix /'ne-/, is of very high frequency. Other glottalized sonorants are found initially, medially, and finally within stems and affixes.

\section{Alternations involving glottalized sonorants.}

3.1. Phonological alternations. Glottalized sonorants do not contrast with plain sonorants in all positions in Yurok. Word-initially $(3 a)$ and postconsonantally $(3 b)$, only plain sonorants are found. ${ }^{4}$ Preceding ejectives $(3 c)$

\footnotetext{
${ }^{3}$ The abbreviation SF indicates that a noun is a short form of a longer word, while UI indicates that a verb is an uninflected stem. Nominal truncation shortens words to the first bimoraic sequence and is discussed further below (see also Blevins 2003a). Uninflected verbs, which can be used wherever inflected verbs occur, are morphological stems, which in some cases have undergone final consonant weakening or loss. Forms attested in Robins (1958) only are followed by [R].

${ }^{4}$ In Robins (1958), stem-initial glottalized sonorants are enclosed in parentheses in the lexicon, to indicate their conditioned neutralization. In Robins's texts, word-initial sonorant preglottalization is written where it was observed phonetically (postvocalically within the same phonological word), and not written where it was not observed (word-initially and postconsonantally). In this paper, forms in virgules are underlying forms, including word-initial preglottalization. Forms not enclosed in virgules are surface phonological representations, and therefore show initial preglottalization only where there is a preceding vowel within the phonological word.
} 
and where a plain-sonorant + glottal stop sequence is expected ( $3 d)$, only glottalized sonorants are found.

(3) Positions of neutralization

A. Plain sonorants only

a. Word-initially

\begin{tabular}{|c|c|}
\hline $\begin{array}{l}\text { leptoyt } \\
\text { yotf }\end{array}$ & $\begin{array}{l}\text { 'hair' } \\
\text { 'boat' }\end{array}$ \\
\hline
\end{tabular}

$b$. Postconsonantally

poy weson 'chief, boss'

cf. numi 'weson 'much the same'

[R:86]

kus wew 'what is her cf. ku'wew 'her name' name?'

B. Glottalized sonorants only

c. Before ejectives

$\begin{array}{lll}\text { hima['r]k'uk } & \text { 'below' [R] } & \text { cf. himar } \\ \text { tf } k^{w} a \text { 'rk' } & \text { 'near' [R] } & \text { 'below' } \\ \text { te'np'- } & \text { 'to own a } & \text { cf. ten- 'to be much', tenowo't } \\ & \text { lot' [R] } & \text { 's/he talks a lot', etc. }\end{array}$

ho'yk'etek' 'I lose'

$d$. Where $\mathrm{R}$ ? is expected

te'nahsp- 'to be drunk' < ten- 'much' + 'ahsp- 'to drink'

cf. tenpey- 'to eat much', tensew-

'to catch a lot', etc.

The facts in (3) suggest the phonological rules or constraints listed in (4), where ' $\mathrm{R}$ is a preglottalized sonorant and $\mathrm{R}$ is a plain sonorant. Deglottalization $(4 a)$ limits surface preglottalized sonorants to postvocalic position within the phonological word. ${ }^{5} \mathrm{~A}$ similar constraint occurs in Yokuts (New-

\footnotetext{
${ }^{5}$ See Blevins (2002c) for discussion of the prosodic or phonological word as domain in Yurok phonology. Compare the variable realization of sonorant preglottalization on the third-person singular prefix 'we- in the examples below, with its consistent realization on the prefixed stem /'yot J/ 'boat'. In (i), the prefix is word-initial and deglottalization (4a) applies to it. In (ii), the phonological word includes a preceding particle $k u$ and preglottalization on the prefix is realized. In (iii), the prefix is again initial within the prosodic word and neutralization occurs, despite a final vowel in the preceding word. In all examples, a surface ['y] occurs in /'yot//, since the phonological word includes the (vowel-final) pronominal prefix.
}
(i) [we-'yót $\left.\int\right]$
'his boat'
(ii) $[\mathrm{ku}$ 'we-'yót $]]$
'the boat of his'
(iii) [céykeni] [we-'yót $\left.\int\right]$
'the child's boat' 
man 1944), Shuswap (Kuipers 1974), and Kashaya (Buckley 1994), with phonetic explanations discussed in Steriade (1999a), Howe and Pulleyblank (2001), and Gordon and Ladefoged (2001). The statements in (4b) express common assimilation of a sonorant to laryngeal features of a neighboring obstruent: in this case, an ejective obstruent appears to give rise to anticipation of laryngeal constriction, resulting in a noncontrastive laryngealization of a preceding sonorant. Laryngeal feature agreement in consonant clusters is also widespread cross-linguistically and appears to have an articulatory and perceptual basis (Steriade 1999 $a$ and Blevins 2002a). In (4c), the cross-linguistic preference for pre- as opposed to postglottalized sonorants is phonologized as a rule of laryngeal metathesis. Similar laryngeal metatheses in unrelated languages are analyzed in Blevins and Garrett (1998; forthcoming). ${ }^{6}$

(4) Some phonological rules/constraints in Yurok

(4a) Deglottalization:

Rule: /' $\mathrm{R} /$ is ' $\mathrm{R}$ after vowels; elsewhere $\mathrm{R}(3 a, 3 b)$.

Constraint: sonorant glottalization must be licensed by a preceding vowel.

(4b) Laryngeal assimilation:

Rule: $\mathrm{R} \rightarrow$ 'R/ _ C' $(3 c)$

Constraint: in RC' clusters, [constricted glottis] is not contrastive for $\mathrm{R}$ which shares this feature with the following segment.

(4c) Laryngeal merger/metathesis:

Rule: an / $\mathrm{R}+1 /$ sequence is realized as ['R] (3d)

Constraint: ${ }^{*} \mathrm{R}$; glottalized sonorants are preglottalized.

In short, the segmental phonology of Yurok glottalized sonorants is unremarkable. Sound patterns similar to those in (4) are attested in other languages and have fairly well understood phonetic origins.

\footnotetext{
${ }^{6}$ The sound change $* \mathrm{R}$ ? > ' $\mathrm{R}$ is a necessary ingredient of Berman's (1982b) analysis of Yurok pronominal prefixes 'ne-, k'e-, and 'we- from earlier $* n^{2} e-$, ${ }^{*} k^{2} e-$, and ${ }^{*} w^{\prime} e-$. These pre-

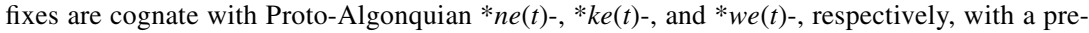
Yurok sound change of $* t>$ ? in unstressed syllables. See Berman (1982b), Goddard (1990), and Blevins (2002b) for further discussion. It is possible to view this as monosegmentalization; once the sequence is interpreted as a single segment, the requirement that glottal constriction precede oral constriction in glottalized sonorants will produce the effect of metathesis.

There are no clear instances where glottal stop and a following sonorant come together across a morpheme boundary; however, there is no evidence anywhere in the language that preglottalized sonorants CONTRAST with glottal stop + sonorant clusters.
} 
3.2. Morphological alternations. Yurok morphology involves at least three distinct cases of laryngealization as part of word formation. As shown in (5), stem-final consonants in third singular indicative unipersonal inflected verbs are laryngealized.

(5) Stem-final laryngealization in third singular indicative unipersonal verbs

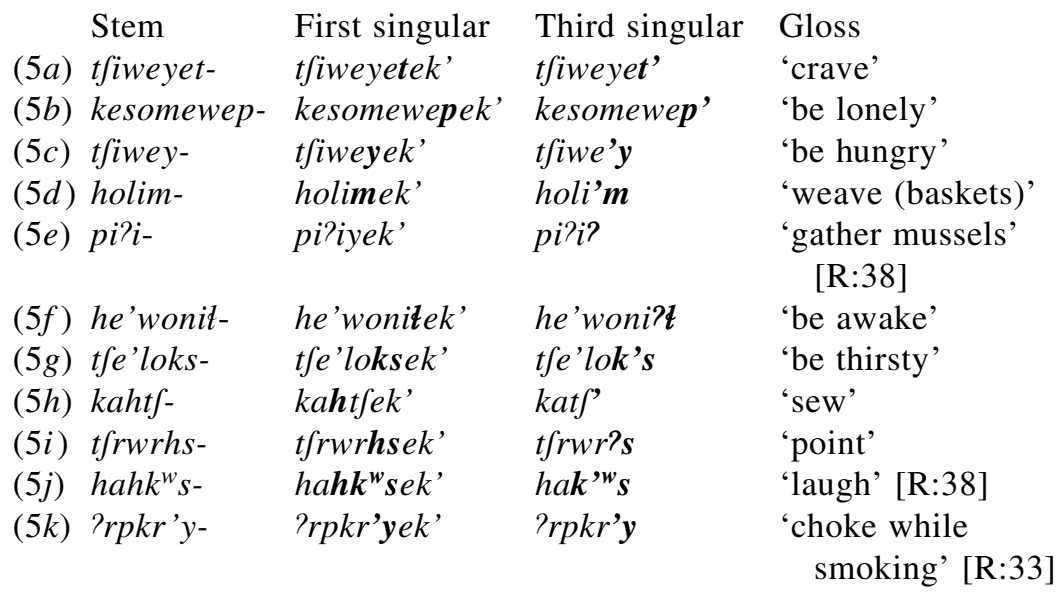

In $(5 a)$ and $(5 b)$, the original stem-final consonant is a plain oral stop, as shown by the first singular form, while the third singular ends in an ejective. In $(5 c)$ and $(5 d)$, the original stem-final consonant is a plain sonorant, while the third singular ends in a preglottalized sonorant. When the stem-final syllable ends in a vowel, a final glottal stop surfaces in the third singular (5e). When the stem-final syllable ends in a fricative, which has no ejective counterpart, a glottal stop occurs immediately preceding the fricative $(5 f)$. In this last case, if the fricative is preceded by an oral stop, the $T$ ? sequence is realized as an ejective $(5 g)$. In all cases where third singular laryngealization affects a syllable with underlying postvocalic $/ \mathrm{h} /,[\mathrm{h}]$ does not surface in the third singular $(5 h-5 j)$. And in the rare cases where the stem itself already contains a glottalized consonant, there is no difference between the bare stem and the third singular form $(5 k){ }^{7}$

The alternations in (5) can be captured by representing the third-person singular inflectional suffix as a floating [constricted glottis] feature, abbreviated as $[\mathrm{cg}]$ below. The feature associates to the final segment of the stem

\footnotetext{
${ }^{7}$ Third singular unipersonal indicatives like those in the third column of (5) also serve as base forms for singular unipersonal imperatives of regular $e$ - and $o$ - class verbs, to which -es or -os is added, respectively (Robins 1958:44-46). So, for the stem holim- 'weave (baskets)' we can compare holimek' 'I weave', holi'm 's/he weaves', and holi'mes 'weave! (sg.)'. The plural imperative takes the bare stem, not the third singular base form: holimek ${ }^{w}$ 'weave! (pl.)'.
} 
if the resulting segment is well-formed (e.g., an ejective or a glottalized sonorant), as shown in $(6 a)$. Elsewhere, the floating feature surfaces as a final glottal stop after a vowel $(6 b)$ and as a glottal stop immediately preceding the stem-final segment if it is a fricative $(6 c){ }^{8}$

(6) Third singular indicative unipersonal inflection as floating [constricted glottis]

(6a) Association (subject to segmental well-formedness)

$$
\begin{aligned}
& \mathrm{C}]_{\text {stem }} \\
& : \\
& {[\mathrm{cg}]}
\end{aligned}
$$

(6b) X-insertion and association

$$
\begin{array}{r}
\mathrm{V}]_{\text {stem }} \mathrm{X} \\
: \\
{[\mathrm{cg}]}
\end{array}
$$

(6c) Elsewhere: prefinal $\mathrm{X}$-insertion and association

$$
\begin{gathered}
\mathrm{XC}]_{\text {stem }} \\
: \\
{[\mathrm{cg}]}
\end{gathered}
$$

The incompatibility of [spread glottis] and [constricted glottis] within the same syllable rhyme is resolved by rule (7). In (7), /h/, the only [spread glottis] segment of the language, deletes when followed by a tautosyllabic segment with [cg] specification.

(7) $h$-loss

$$
\left.h \rightarrow \emptyset / \mathrm{V}_{-} \ldots \underset{\mathrm{I}}{\mathrm{X}} \ldots\right]_{\text {syllable }}
$$

While it is tempting to attribute the patterns of association in (6) to aspects of universal grammar, a brief consideration of other (unrelated) languages with similar floating laryngeal features illustrates the necessity of languagespecific information in these statements. In Klamath (Blevins 1993:263-67), a floating $[\mathrm{cg}]$ occurs both stem-finally and suffix-initially. Patterns of association in Klamath are nearly identical to those in Yurok with one major exception: if $[\mathrm{cg}]$ shows up in non-prevocalic position in Klamath, where it is illicit phonotactically, it does not surface at all. This contrasts with the Yurok pattern captured by $(6 c)$ above, where an otherwise illicit word-final fricative + glottal stop sequence undergoes metathesis, with a glottal stop surfacing.

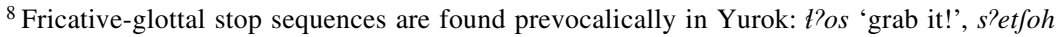
'horn', etc.
} 
One can also compare the Yurok and Klamath patterns with suffix-initial floating [cg] in Yokuts (Newman 1944 and Archangeli 1983; 1984). Unlike Yurok and Klamath, Yokuts suffix-initial floating [cg] merges segmentally with only sonorants, not with obstruents, though Yokuts does have a class of ejectives. As in Klamath, Yokuts floating [cg] does not surface where phonotactically illicit. Since both Klamath and Yokuts have epenthesis rules which apply in other environments, the failure of floating [cg] to trigger epenthesis is notable. ${ }^{9}$ In sum, though the Yurok pattern suggests that phonotactic operations (metathesis, epenthesis, etc.) may be invoked to ensure the surface realization of a floating feature, Klamath and Yokuts illustrate cases where phonotactic operations are not invoked, and the floating feature fails to surface. In addition, though segmental hosts for floating [cg] in languages like Yurok and Klamath appear to be just those defined by the segment inventory, there are languages like Yokuts where hosts are only a subset of those expected under structure preservation. In the following discussion, we see that Yurok also has target restrictions on segmental glottalization.

The alternations in (5) involve obstruents and sonorants, but there are two other morphological processes in Yurok where only sonorants are glottalized. One is in vocatives derived from kinship terms. In (8a), vocatives show final glottalized sonorants which are absent in nonvocatives, whether the nonvocative is pronounced in its full form or in its short (truncated) form. ${ }^{10}$ In $(8 b)$, vocatives with final obstruents are shown for comparison: these forms do not show final ejectives.

(8) Sonorant glottalization in vocatives

$\begin{array}{clll}\text { (8a) } \begin{array}{ll}\text { Full form } \\ \text { tulos }\end{array} & \text { Short form } & \text { Vocative } & \text { Gloss } \\ \text { tfim } & \text { tul } & \text { tfi'm } & \text { 'uncle' } \\ \text { pinos } & \text { pin } & \text { tu'l } & \text { 'aunt' } \\ \text { (8b) } \text { pitfowos } & \text { pitf } & \text { 'elder sister' } \\ \text { kutfos } & \text { kutf } & \text { kutf } & \text { 'grandfather' } \\ \text { totos } & \text { tot } & \text { tot } & \text { 'grandmother' } \\ \text { kokos } & \text { kok } & \text { kok } & \text { 'father' } \\ & \text { tfitf } & t f i t f & \text { 'younger sibling' }\end{array}$

${ }^{9}$ In Klamath and Yokuts and in Yurok, the floating feature surfaces as a glottal stop intervocalically, so the argument cannot be made that the failure of epenthesis is a direct consequence of rules prohibiting insertion of timing slots or syllable onsets.

${ }^{10}$ Nominal truncation in Yurok is detailed in Blevins (2003a) and discussed further in 4. Sonorant glottalization may have prosodic origins, occurring in stressed, lengthened monosyllables. Two pronouns appear to have undergone this historical laryngealization: $k e$ ' $l$ 'you sg.' (<*kel, cf. Yurok kelew 'you pl.', Proto-Algonquian *kiila 'you sg.') and ko'l 'some, something' ( $<* k o l$, cf. Yurok kolin 'one, a'). 
It is not clear to what extent vocative formation is synchronically productive. A productive rule might take the form of (9): association of a floating [cg] to the final sonorant of a nominal short form.

(9) Vocative floating [constricted glottis] association

$$
\begin{gathered}
\mathrm{R}]_{\text {Nom/sF }} \\
: \\
{[\mathrm{cg}]_{\text {Vocative }}}
\end{gathered}
$$

A final set of alternations between plain and glottalized sonorants occurs in certain noun/verb pairs. Nominalizations with final glottalized sonorants are shown in $(10 a)$, along with the verb stems from which they appear to be derived..$^{11}$ In $(10 b)$, similar nominalizations with final obstruents are shown for comparison: these forms do not show final ejectives or ${ }^{7} C$ clusters.

\begin{tabular}{|c|c|c|c|c|}
\hline \multirow{3}{*}{$(10 a)$} & $\begin{array}{l}\text { Nominalization } \\
\text { tfurp'r'y }\end{array}$ & $\begin{array}{l}\text { Gloss } \\
\text { 'comb' }\end{array}$ & $\begin{array}{l}\text { Verb stem } \\
\text { tfurp'ry }\end{array}$ & $\begin{array}{l}\text { Gloss } \\
\text { 'comb, UI' }\end{array}$ \\
\hline & $k^{w}$ esaaye'le'w ${ }^{12}$ & 'hoarse person' & $k^{w}$ esaalew- & 'be hoarse' \\
\hline & $k^{w}$ ere'we'y & 'dugout canoe' & $k^{w}$ ere'wey- & $\begin{array}{l}\text { 'have a pointed } \\
\text { face' }\end{array}$ \\
\hline & mewi'm & 'widower' & mewim-rt & $\begin{array}{l}\text { 'become frail } \\
\text { (of men) UI' }\end{array}$ \\
\hline & $l-e \gamma-a a^{\prime} \boldsymbol{y}$ & 'doorway, path' & laay- & 'pass' \\
\hline & $l-r \gamma-r^{\prime} l$ & 'buzzard' & lol- & 'fly' \\
\hline & $t-e \gamma-e^{\prime} y$ & 'flea' & teyk-elum- & 'bite' \\
\hline$(10 b)$ & l-e $\gamma$-ets & 'mudhen' & letfketf- & 'pull out' \\
\hline & $m-e \gamma-u t$ & 'store, peddlar' & mulkotf- & 'sell' \\
\hline & $m-e \gamma-o k^{w}$ & 'dog' & mok $^{w}$ omok ${ }^{w}$ otf- & 'bark' \\
\hline & $p l-e \gamma-o k$ & $\begin{array}{l}\text { 'headband of } \\
\text { woodpecker } \\
\text { scalps' }\end{array}$ & ploks- & $\begin{array}{l}\text { 'be big (of flat } \\
\text { things)' }\end{array}$ \\
\hline & sw-er-et & 'gunshot' & swetk- & $\begin{array}{l}\text { 'be scattered, } \\
\text { burst' }\end{array}$ \\
\hline
\end{tabular}

(10) Sonorant glottalization under nominalizations [R, B]

\footnotetext{
${ }^{11}$ In the last three examples of $(10 a)$, the nominalization includes the habitual infix -e $\gamma$ - and its rhotic-harmony variant $-r \gamma$-. Literal glosses for 'trail', 'buzzard', and 'flea' would be 'that which habitually passes', 'that which habitually flies', and 'that which habitually bites'. The abbreviation UI stands for "uninflected verb" - a verb which lacks inflectional suffixes—and may be further shortened.

${ }^{12}$ In this form, glottalization also appears on a preceding sonorant consonant. This double glottalization could be a case of the regressive (phonetic) laryngealization discussed in $\mathbf{3 . 3}$, allowing one to maintain underlying $/ 1 /$.
} 
At first glance, the nominalizations in $(10 a)$ might be analyzed as thirdperson singular inflected unipersonal verb forms, like those shown in (5). As such, for example, the word for 'dugout canoe', $k^{w} e r e$ 'we' $y$, would mean literally 'it has a pointed face'. However, there are at least two reasons to believe that the nominalizations in (10) constitute distinct forms from thirdperson singular inflected indicative verbs. First, though final obstruents are glottalized in third singular inflected unipersonal indicatives, the final obstruents in $(10 b)$ do not surface as ejectives or final glottal stop + fricative clusters. Second, a number of the nominalizations in (10) are clearly derived from uninflected verb forms (UI), which, as their label indicates, are verbs which lack final inflectional suffixes. Uninflected verbs also appear to lack the final derivational element of the verb stem: hahpelin 'to be lively/uI' from inflectional stem hahpelin-ep-; kaamer 'to be bad weather/UI' from inflectional stem kaame $\gamma$-et-; noson 'to be helpful/uI' from inflectional stem noson-ow-, etc. A clear example is the noun tere'y 'flea' (literally, 'that which bites habitually'), which is derived from the uninflected verb tey 'bite', which itself is found in the inflecting stems teykelum- 'to bite' and teykelut- 'to be a biter (of a dog)'. Since uninflected stems are incompatible with inflection, the glottalization in the nominalized form te re' $y$ cannot be attributed to third-person singular indicative inflection.

The numerous place-names with this form of nominalization (Waterman 1920) and words of the same pattern likely introduced since contact (e.g., me rut 'store') suggest that this word-formation process is productive. The productive rule can be stated as in (11): a verb becomes a noun by association of a floating [constricted glottis] feature to the final sonorant of the uninflected verb.

(11) Nominalizing floating [constricted glottis] association

$$
\begin{aligned}
& \mathrm{R}]_{\text {Verb/UI }} \\
& : \\
& {[\mathrm{cg}]_{\text {Nominalizer }}}
\end{aligned}
$$

The restriction of floating $[\mathrm{cg}]$ association to sonorants under vocative and nominalizing morphology is not unique to Yurok. Recall from the brief discussion above that a similar restriction is necessary in Yokuts, where suffix-initial floating [cg] can associate with sonorants but not obstruents. In derivational processes, a similar pattern is found in Spokane and other Interior Salish languages where, under diminutive glottalization, all sonorants in the word are glottalized, but obstruents are unaffected (Nichols 1971).

3.3. Phonetic alternations. In addition to the regular phonological and morphological alternations resulting in surface preglottalized sonorants, glottalization may also be the result of a gradient optional phonetic process. 
Plain sonorant domains preceding syllable-final ejectives or preglottalized sonorants are optionally produced with audible creaky voice, whose intensity decreases with distance from its phonological source. ${ }^{13}$ In (12), some of the same verb forms listed in (5) are shown again, this time with an underline indicating the optional domain of creaky voice.

(12) Laryngeal spread (optional laryngealized domain underlined)

$\begin{array}{llll}\text { Stem } & \text { First singular } & \text { Third singular } & \text { Gloss } \\ \text { tfiweyet- } & \text { tfiweyetek' } & \text { tifiweyet' } & \text { 'to crave' } \\ \text { kesomewep- } & \text { kesomewepek' } & \text { kesomewep' } & \text { 'to be lonely', } \\ \text { tfiwey- } & \text { tfiweyek' } & \text { tfiwe'y } & \text { 'to be hungry' } \\ \text { holim- } & \text { holimek' } & \text { holi'm } & \text { 'to weave (baskets)' }\end{array}$

The domain of this optional spread appears to be the phonological word, where every phonological word has at least one word stress (Blevins 2002c). A word like lá:yolumek' 'I'm teaching' can be produced with creaky voice from the start: lá:yolumek'. The same is true in particle + verb constructions which form a single phonological word. The command nu nép's 'go eat! (sg.)' is optionally nu nép's, with audible creak in the unstressed preverbal particle, which is arguably part of the same phonological word as the inflected verb. However, in phrases composed of two phonological words, like nrmŕm nép' 'my son is eating', variants include nrmŕm nép' and nrmŕm nép', but not **nrmŕm nép'. This language-specific phonetic realization of phonological [cg] is stated in (13).

(13) Laryngeal spread in Yurok

Laryngealization/creak associated with a syllable-final consonant other than glottal stop optionally spreads leftward through plain voiced sonorants within the prosodic word, but is blocked by obstruents and $/ \mathrm{h} /$.

This phonetic process is mentioned for the sake of completeness and is not typologically unusual (Gordon and Ladefoged 2001). In the discussion which follows, I focus on glottalized sonorants which are present underlyingly or which surface via one of the phonological or morphological processes described above, abstracting away from the variable effects of (13).

\footnotetext{
${ }^{13}$ In the word paa? 'no', there is optional creak on the long vowel preceding final glottal stop, but phonetic laryngealization of the sort described in the text appears to be generally less common with final glottal stop than with final ejectives or preglottalized sonorants. This phonetic spread of laryngealization across sonorant domains appears to be the source of historical glottal stop metathesis in many forms, including the first-person possessive 'ne-<*ne-'- <*ne-t(see n. 6) and the shift of glottalization in imperative verbs like non'owos < *nono'wos '(you sg.) fetch it!'.
} 
4. Preglottalized sonorants as single segments. The segmental inventory in (1) represents Yurok preglottalized sonorants as single phonological segments. An alternative which must be considered is that preglottalized sonorants are phonologically clusters of glottal stop + sonorant. ${ }^{14}$ In this section I justify the single-segment analysis by highlighting ways in which preglottalized sonorants pattern with other single segments in a range of sound patterns.

4.1. In alternations involving glottalization. Section 3 presents a range of contexts in which glottalized and plain sonorants alternate. Recall that in third-person singular verb forms like those shown in (5), stem-final oral stops and affricates are realized as ejectives, while final sonorants are realized as preglottalized. If, as suggested above, the third-person suffix is represented as a floating [cg] feature, then the parallelism of ejectives and preglottalized sonorants suggests that preglottalized sonorants are single segments. However, this segmental parallelism is weakened by the behavior of voiceless fricatives: recall that under third-person laryngealization, stemfinal fricatives are realized as glottal stop + fricative clusters.

A stronger argument from the data presented in $\mathbf{3}$ above relates to the rule of sonorant deglottalization stated in $(4 a)$. Glottalized sonorants which are not preceded by vowels within the phonological word neutralize to plain sonorants. If glottalized sonorants are analyzed as $\mathrm{R}$ clusters, then this rule would be the only rule of word-initial cluster simplification in the language. ${ }^{15}$ Cross-linguistically, rules of laryngeal feature neutralization at word edges typically effect segment-internal feature specification, not cluster simplification (Steriade 1999a). The same is true of laryngeal feature assimilation like that formulated in $(4 b)$. If preglottalized sonorants are treated as clusters, then, just in case an ejective is preceded by a plain sonorant, a glottal stop must be inserted preceding the sonorant. Such segment insertion rules, like the cluster simplification schema just mentioned, are anomalous in the crosslinguistic literature on laryngeal neutralization, where the domain of neutralization is typically the segment. ${ }^{16}$ However, the strongest arguments for preglottalized sonorants come from two sound patterns not yet discussed: the prosodic morphology involved in nominal truncation, and vowel lowering of /e/ to [a]. I discuss each of these in turn.

\footnotetext{
${ }^{14}$ Recall from n. 8 that fricative $+?$ clusters occur word-initially. In word-final position, however, a fricative + glottalization is realized as a ? + fricative cluster, as described below.

${ }^{15}$ One might attempt to relate a unique cluster simplification rule to sonority within the onset. An argument would have to be made that $/ 7 /$ is more sonorous than $/ \mathrm{w}, \mathrm{y}, 1, \mathrm{r}, \mathrm{m}, \mathrm{n} /$ and, for this reason, it is deleted. Under this analysis, however, the absence of syllable-initial /R?/ clusters would be unexplained. Note that Yurok allows word-initial OO ( $t \int k, t^{\prime} p$ ', etc.), RR ( $m y)$, and $\mathrm{OR}$ ( $p l, k n, t m$, etc.) onsets, where $\mathrm{O}$ is an obstruent and $\mathrm{R}$ a sonorant.

${ }^{16}$ For a detailed cross-linguistic survey of laryngeal neutralization, see Steriade (1999a).
} 
4.2. In nominal truncation. Yurok has a productive rule of nominal truncation in which polysyllabic nouns are shortened to monosyllables (Blevins 2003a). Examples given in (14) illustrate that, independent of the shape of the initial syllable of the long form, the truncated short form of the word is made up of the first $\mathrm{C}_{0} \mathrm{VC}$ or $\mathrm{C}_{0} \mathrm{~V}$ : syllable of the word. The general rule truncating words to minimal bimoraic syllables is stated in (15).

(14) Nominal truncation (periods mark syllable boundaries)

Initial syllable of long form

$\mathrm{C}_{1} \mathrm{~V}$

le.wet

tfe.lo. raa.pit

Short form

Gloss

tfi.no.me.wes

lew

'net'

wr.try

tfel

'rib(s)'

mi.tfos

'young man'

'tail'

te. $k^{w}$ o.nek ${ }^{w} s$

mits

$t e k^{w}$

'brother'

'box'

$\mathrm{C}_{1} \mathrm{VC}$

mrw.prh

mrw

skry.trk'w

skry

wen.tfok ${ }^{w} s$

wen

met.kwet

pek.tfitf

met

k'ep'.tf'em

pek

$\mathrm{C}_{1} \mathrm{Vh}$

tfah. $k^{w}$ oh

k'ep'

/'lahp.sew/

tfah

nrh.pry

pah.tun

toh.pew

?ah.ke.tfoyp'

lah

nrh

pah

toh

?ah

$\mathrm{C}_{1} \mathrm{~V}^{\text {? }}$

wo.?o.mehl

wo?

ka.?a'n

$k a$ ?

/'wr't.pi.trk/

$w r ?$

'lunch, packed food'

'woman's dress'

'woman'

'cane'

'thread, string, rope'

'daughter-in-law'

'trousers, pants'

'plate'

'berry'

'neck'

'hole'

'thorn, prickle'

kya't.?o:?

$\mathrm{C}_{1} \mathrm{~V}$ :

pa: $\gamma o h$

kya?

tr:.kun

pa:

wo:.met

tr:

ha: lop

wo:

'shelled acorn'

ro:.tah

ha:

ro:

ka:.mu:ks

ka:

'blanket'

'root'

'ulcer, sore'

'brother (of a man)'

'head of fish'

'acorn'

'clear pitch'

'sunray; time'

'bastard'

(15) Yurok truncation

Word $=[\mu \mu] \sigma$ 
Long forms of words are shortened by taking the shortest initial string of the long form which is consistent with (15).

Notice that in (14), ejectives pattern as single segments (e.g., k'ep' from k'ep'tf'em), while preglottalized fricatives pattern as bisegmental sequences (e.g., $w r$ ' from /'wr'lpitrk/). The data in (16) show that preglottalized sonorants pattern as single segments, giving rise to truncated nouns with final glottalized sonorants. ${ }^{17}$ If the glottalized sonorants in the long forms in (16) were clusters, we would expect the unattested short forms ${ }^{* *} c n e$ ?,$* * k e$ ? , and $* * ? o$ ? for these words.

(16) Glottalized sonorants in truncated forms

Initial syllable

of long form

$\mathbf{C}_{1} \mathbf{V}^{\prime} \mathbf{R}$

Long form

Short form

Gloss

tfne'wk'w os

tfne'w

'son-in-law'

ke'mow

ke'm

'food'

?o'let

?o'l

'house'

4.3. In vowel lowering. A final argument for preglottalized sonorants as single segments involves the near-complementary distribution of short $e$ and $a$ in Yurok (Blevins 2003b). The general complementary distribution of short $e$ and $a$ is illustrated in (17).

(17) Partial complementary distribution of $e$ and $a$

$\begin{array}{lll} & \text { Attested } & \text { Unattested/rare } \\ \text { Short } & i h ., \text { h., oh., rh., ah. } & \text { eh. } \\ \text { i?., u'., o?., r'., a?. } & e ? . \\ \text { ir., ur., or., ar. } & \text { er. }{ }^{18} \\ \text { i'r., u'r., o'r., a'r. } & e^{\prime} r .\end{array}$

Short elsewhere:

$i, u, o, r, e$

$a$

Before tautosyllabic glottal stop and before tautosyllabic /r/ and /'r/, $a$ is found. However, before other tautosyllabic consonants, including /'y, 'l, 'm, ' $\mathrm{n} /, e$ is found to the exclusion of $a$. Compare, for example, [nep.set [] 'my father' (/'ne-pset//) with [nar.pel] 'my tooth' (/'ne-rpel/)/. The examples in (18) are representative of the distributional generalizations shown in (17).

\footnotetext{
${ }^{17}$ Syllabification of long forms is purposely omitted from the data in (16). The syllabification of preglottalized sonorants is discussed in detail in $\mathbf{5}$.

${ }_{18}$ There appears to be a general ban on syllables with rhotic vowels in the nucleus and /r/ in the coda or onset.
} 
(18) Short vowel contrasts

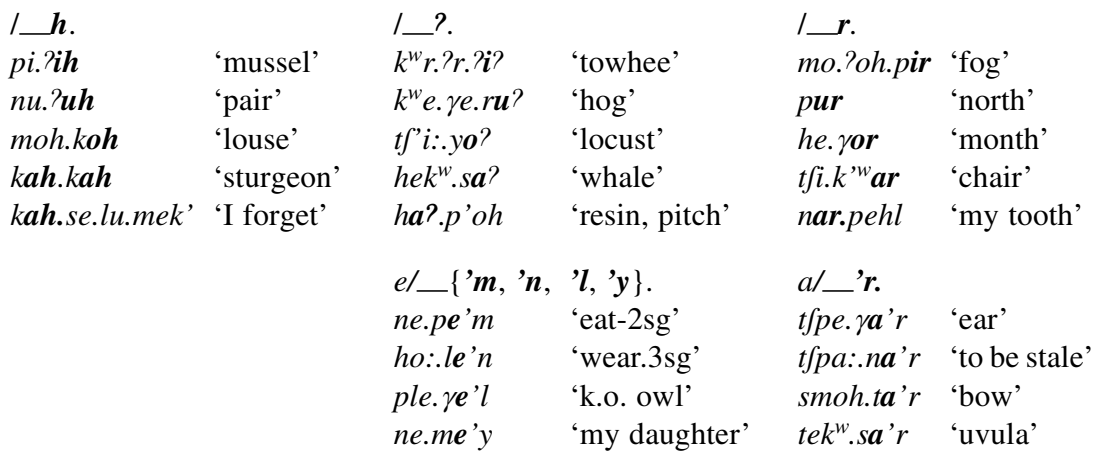

Blevins (2003b) suggests the sound changes in (19), where (19a) is complete and $(19 b)$ constitutes a sound change in progress. As a result of (19a), there are no tautosyllabic $e^{?}$ or $e h$ sequences in Yurok.

(19) Two rules of $e$-lowering

(19a) Prelaryngeal lowering

(19b) Prerhotic lowering

$$
\begin{aligned}
& * e>a /-\{\mathrm{h}, ?\} . \\
& * e>a /-\left\{\mathrm{r},{ }^{\prime} \mathrm{r}\right\} .
\end{aligned}
$$

If preglottalized sonorants are truly glottal stop + sonorant clusters, then all are expected to trigger synchronic prelaryngeal lowering, but they do not, as shown by forms like nepe'm, ho:le' $n$, plere'l, and neme'y in (18).

5. Segmental fission under syllabification. Though there appears to be solid evidence that preglottalized sonorants are single segments in Yurok, there is also clear support for their syllabification as clusters in intervocalic position. Before looking at the data, general principles of Yurok syllabification are discussed, along with the nature of syllabification judgments.

5.1. Syllables and syllabification in Yurok. Native speakers of Yurok have little problem identifying the number of syllables in a word and, when asked to speak slowly, naturally break words into component syllables. Of particular note is the fact that speakers who broke words into syllables in slow speech are consistent in where they pause. In addition, several writing systems in use by the Yuroks, including Unifon and the New Yurok Alphabet adopted by the Yurok Tribal Language Committee, mark syllable breaks with hyphens. ${ }^{19}$ In these systems, no one has taught the users where to put

\footnotetext{
${ }^{19}$ Unifon, an alphabetic system, was introduced to the Yurok in the late 1960s. Hyphens were used to mark syllable breaks, but where these breaks occurred was left to native-speaker intuitions. For the inventory of Yurok Unifon symbols and illustrations of their use, see Jesse Exline's Yurok Dictionary.
} 
the hyphens, so we can assume that these represent some natural structure within the spoken word. Exline (n.d.) contains hundreds of Yurok words in Unifon, with syllable breaks marked, and To the American Indian by Lucy Thompson (1991), first published in 1916, contains over 150 hyphenated words and phrases in her own orthography. When syllable breaks are marked in this paper, they are based on slow speech and native-speaker writing conventions. Since these breaks are consistent across speakers, they are taken to reflect a significant aspect of Yurok sound structure. ${ }^{20}$

The general constraints on Yurok syllable structure are fairly simple. There are no onsetless syllables. All words begin with a nonsyllabic element (a consonant or glide) and medial VCV sequences are syllabified V.CV. Intervocalic biconsonantal clusters are heterosyllabic, so medial VCCV is syllabified VC.CV. A limited number of complex onsets and complex codas are allowed word-initially and word-finally, respectively; however, medial CCC clusters are rare and are most often the result of root/stem compounding or reduplication, maintaining the root/stem syllabification. In stressed open syllables, the following consonant can be somewhat lengthened: VCV > VC: V. This gemination, most common in sonorants, is sometimes written (e.g., by Thompson 1991 [1916] and Spott and Kroeber 1942) or represented by CVC-V syllabification in this context (Exline [n.d.]). In (20), nativespeaker syllabifications taken from my own fieldnotes illustrate the general constraints just stated. Note that in $(20 c)$, the syllabification of $/ \mathrm{tm} /$ and $/ \mathrm{t} \mathrm{jm} /$ into different syllables occurs, despite the existence of these clusters wordinitially: tmenomen 'half', tfmeya:n 'yesterday'.

(20) General constraints on Yurok syllabification

(20a) Initial CV (onsetless syllables are unattested) nu:k.soh 'my children' hu:k.soh 'children' no.li.mek' 'that I weave' ho.li.mek' 'I weave'

\footnotetext{
${ }^{20}$ It is true that some writers of Yurok have had exposure to English writing and its arbitrary conventions of syllabification. However, it is doubtful that this has had an effect on how Yurok is written by those with Yurok as a first language since (i) syllabifications are consistent with syllable-by-syllable slow speech (including the speech of those with rudimentary literacy skills) and (ii) syllabifications appear to be consistent across native speakers. As far as I am aware, there is no Yurok tradition, teaching, or custom which relates to transcription of slow or natural speech. It is this slow speech which appears to be the basis of the placement of hyphens in Unifon and the writing system devised by Lucy Thompson. I have observed the use of hyphenation in both Yurok language classes and master-apprentice sessions and, in both settings, hyphenation was based on slow speech, uttered in a syllable-by-syllable fashion. In a few places, Exline (n.d.) deviates from this practice: one is where the hyphen is used to mark the boundary between verb stem and inflectional suffixes.
} 
(20b) Medial V.CV

\begin{tabular}{|c|c|}
\hline se. үep & $\begin{array}{l}\text { 'coyote' } \\
\text { 'tomorrow' }\end{array}$ \\
\hline
\end{tabular}

(20c) Medial VC.CV

$\begin{array}{llll}\text { hek }^{w} . s a & \text { 'whale' } & \text { moh.koh 'louse' } \\ \text { tfey.ke.ni } & \text { 'little one' } & \text { mun.tfey } & \text { 'white' } \\ \text { hot.mon } & \text { 'baby rabbit' } & \text { hitf.mey } & \text { 'the day before yesterday' }\end{array}$

5.2. The syllabification of intervocalic preglottalized sonorants. Since there is good evidence that preglottalized sonorants are single segments, and the general pattern for single segments is to syllabify as onsets intervocalically (20b), it is somewhat surprising to find that native speakers consistently syllabify intervocalic preglottalized sonorants as if they were clusters, with a glottal stop closing one syllable and a sonorant serving as onset of the next. The data in (21) show syllabifications from three different native speakers transliterated, where necessary, into the present orthographic system. ${ }^{21}$ Recall that in both Unifon and the New Yurok Alphabet, syllable breaks are represented orthographically by hyphens.

(21) Native speaker syllabification of intervocalic preglottalized sonorants

(21a) Syllabifications of preglottalized sonorants from Exline's Yurok Dictionary

$\begin{array}{llll}\text { to'.woh } & \text { 'enough' } & \text { no:'.rep' } & \text { 'he follows' } \\ \text { he'.mi' } & \text { 'pigeon' } & \text { me'.yet } & \text { 'nettles' } \\ \text { me'.re.po.yoh } & \text { 'file (tool) } & \text { nahtf.pu.me'.moh } & \text { 'we allow' } \\ \text { ne.pe'.wif } & \text { 'fish' } & \text { tfye'.wol } & \text { 'to make music' } \\ \text { 'o'.ro.wi' } & \text { 'dove' } & \text { pe'.we.te'w } & \text { 's/he washes } \\ & & \text { hands' } \\ \text { ko'.moy } & \text { 'hear' } & \text { te'.no.yok' } & \text { 'I feel insulted' }\end{array}$

(21b) Syllabifications of preglottalized sonorants from Trull (2001) and Inong (2002)

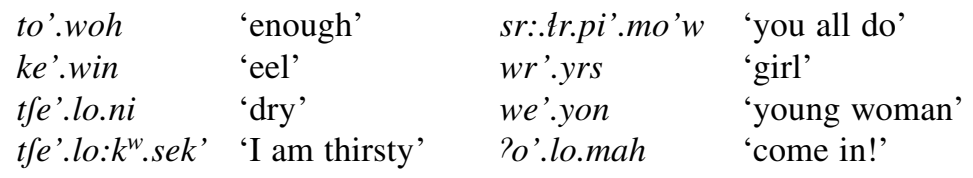

${ }^{21}$ To preserve identity between preglottalized sonorants as shown in (1) and their bisegmental counterparts under syllabification, I continue to write the glottal portion of the segment with an apostrophe. 
(21c) Syllabifications of preglottalized sonorants from slow speech of A. Figueroa

$\begin{array}{llll}\text { to'.woh } & \text { 'enough' } & \text { ke'.yo.lew } & \text { 'spit' } \\ \text { he'.mi' } & \text { 'pigeon' } & \text { he.lo.me.ye'.moh 'we all dance' } \\ \text { ke'.win } & \text { 'eel' } & \text { ko'.mo.yok' } & \text { 'I hear' } \\ \text { tfe'.lo:k'.sek' } & \text { 'I am thirsty' } & \text { to:'.mar } & \text { 'friend' } \\ \text { ?o'.ro.wi? } & \text { 'dove' } & \text { re'.noh } & \text { 'feather' }\end{array}$

The syllabification pattern in (21) is consistent across speakers but inconsistent with the treatment of preglottalized segments as single phonological segments. One might argue that the bisegmental behavior of preglottalized sonorants intervocalically is the consequence of production constraints unrelated to their phonological representation. Anticipating part of the analysis to come, recall that Yurok has no vowel-initial syllables and, furthermore, that preglottalized sonorants do not occur word-initially. When asked to say a word like ke'win 'eel' slowly (where // indicates pause), neither ke // 'win nor $k e$ ' $w / /$ in is possible, because in both cases the second syllable, which now constitutes a prosodic word, begins with an unpronounceable syllable type. Under this account, the facts in (21) stem from performance factors which may be independent of phonological representations (Harris 1999). While I build on the word-based nature of this analysis below, I first show that basic Yurok stress patterns take as input syllabifications like those shown in (20) and (21). Since syllabification plays a role in stress patterns, syllabifications, including those in (21), must be recognized as part of Yurok phonology and demand a general explanation.

5.3. Evidence from stress. A preliminary account of Yurok nominal stress is presented in Blevins (2003a). A three-way division of weight is evident in Yurok. Syllables with long vowels are the heaviest and always attract word stress. In the absence of long vowels, closed syllables attract stress; and in the absence of closed syllables, open light syllables may also carry primary stress. For the purposes of this discussion, we can compare patterns of even stress (ss) which occur in disyllabic words where both syllables are heavy (22), and the seeming iambic (ws) pattern which occurs in disyllabic words with light-heavy syllable sequences (23).

(22) Even stress in [HH] disyllables

$\begin{array}{ll}(22 a) \text { láhp.séw } & \text { 'plate' } \\ (22 b) \text { mét.k'ét } & \text { 'cane' } \\ (22 c) \text { póp.séw } & \text { 'bread' } \\ (22 d) \text { hín.két } & \text { 'white oak' } \\ (22 e) \text { kíkw.tén } & \text { 'moss' } \\ (22 f) \text { nŕh.pŕy } & \text { 'berry' }\end{array}$


(22g) ?ó.lét 'house'

(22h) ké.wín 'eel'

(23) Final stress in [LH] disyllables

(23a) 'e.káh 'cap'

(23b) we.róy '3sg-stream'

(23c) ne.púy 'salmon'

(23d) ko.wí 'stick'

(23e) tfe.tfék $k^{w} \quad$ 'fish bones'

(23f) pr.yís 'golden eagle'

(23g) tfe.win 'mother-in-law'

(23h) Pr.wŕn 'salmonberry'

Note that in $(22 g)$ and $(22 h)$, the intervocalic preglottalized sonorant acts as a bisegmental sequence for the purposes of syllabification and stress. In these examples, and others like them, the "sprung off" glottal segment serves to close the preceding syllable, making it heavy for the purposes of the stress rule. In the following section, I attempt to motivate this segmental fission by general surface-based syllabification algorithms.

Before doing so, recall that within Yurok, /e/ is never followed by tautosyllabic glottal stop. Given the syllabifications in (21), it is clear that there is one potential class of exceptions to this. As shown in (24), glottalization which has sprung off of a glottalized sonorant under syllabification does not trigger lowering of $e$ to [a]. ${ }^{22}$

(24) Intervocalic preglottalized sonorants do not trigger /e/-lowering

\begin{tabular}{|c|c|c|c|}
\hline$e l-\left\{{ }^{\prime} \mathbf{m},{ }^{\prime} \mathbf{n}\right.$ & $\left.,{ }^{\prime} \mathbf{l}, ' \mathbf{y}\right\} \mathbf{V}$ & $e l-{ }^{\prime} \boldsymbol{V} \boldsymbol{V}$ & \\
\hline ke'.mow & 'food' & t $\int p \boldsymbol{e}^{\prime}$.roy.ok' & 'I listen' \\
\hline te'.nahs.pet & 'they are drunk' & me.ne'.ru.tek' & 'I make way for' \\
\hline $\begin{array}{l}\text { tfe'.lo:k.sek' } \\
\text { ke'.yo.lew }\end{array}$ & 'I am thirsty' & pe'.ro.no.ni & 'big (of houses)' \\
\hline
\end{tabular}

If we assume that the sound change in (19) occurred prior to the existence of syllabifications like those in (24), then nothing more need be said. If, on the other hand, a synchronic constraint barring tautosyllabic $e^{\text {? }}$ is posited, then it must apply to a level of representation in which intervocalic preglottalized sonorants are single segments, not clusters.

5.4. Motivating fission: surface word-based syllabification. Syllables are important constructs in phonological systems, as they serve as the bearers of stress, the domains of harmony, and as templates for prosodic morphology (Blevins 1995). However, it is also clear that syllable structure is

${ }^{22}$ Recall that the voiced velar fricative $\gamma$ behaves as a sonorant in this respect: ? $e$ ' $\gamma a h$ 'to eat in a group; meal', ? $e$ ' $\gamma u r$ 'basket used in White Deerskin Dance', etc., with no lowering of /e/. 
usually predictable in a language. Although in some exceptional cases, nongliding vowels or nonvocalizing glides must be lexically specified, syllable structure and syllabicity alternations can, for the most part, be derived from the segmental properties of phonological forms. The derived status of syllabification is consistent with the fact that syllabifications within a given language are never contrastive (Blevins 1995 and Steriade 1999b). However, since stress patterns and syncope alternations in many languages are sensitive to syllable structure, syllabifications cannot be purely surface phenomena either.

Evidence summarized in $\mathbf{4}$ suggests that preglottalized sonorants in Yurok are single segments. However, syllabification, and stress patterns sensitive to syllabification, treat intervocalic preglottalized sonorants as heterosyllabic glottal stop + sonorant sequences. How can the monosegmental and bisegmental interpretations of glottalized sonorants be accounted for in one and the same language? What aspects of Yurok phonology give rise to apparent segmental fission intervocalically but not word-finally ( $k e^{\prime} m$ 'food') and preconsonantally (ti'n.pe.lah 'yellow')? I suggest that intervocalic fission of preglottalized sonorants is motivated directly by surface word-level phonotactics. In particular, the fact that all words begin with consonants and that no words begin with preglottalized sonorants can be seen to motivate fission in all words which pattern like those in (21).

Empirical evidence for syllabifications based on surface word-edge phonotactics is presented in Steriade (1999b) and Blevins (2002a). These studies note two significant aspects of native-speaker word-internal syllabification judgments. First, in many languages, word-internal syllabification judgments vary across speakers. Second, this variation correlates with contexts in which word-internal strings cannot be parsed as a sequence of word-initial and word-final strings. ${ }^{23}$ In some languages, like Spanish and many dialects of Arabic, all word-internal strings can be parsed as sequences of word-initial and word-final sequences. As a consequence, syllabification judgments are consistent across speakers. In other languages, like English, even some of the simplest words give rise to uncertainty on the part of speakers. For example, the word lemon in American English is problematic since syllabifications le.mon and lem.on yield syllable types which are not found at word edges. In the first case, $[1 \varepsilon]$, a final nonlow lax vowel is parsed, though such lax

\footnotetext{
${ }^{23}$ Additional facts motivating word-based syllabification are found in Oykangand and Arrernte, where word-medial codas are maximized to the exclusion of onsets (Sommer 1969; 1970 and Breen and Pensalfini 1999). The rare syllabification of VCV as VC.V in these languages can be directly related to the predominant pattern of vowel-initial, consonant-final words. See Steriade (1999b) and Blevins (2002a) for further discussion of word-based syllabification, and Harris (1999) for complementary evidence that prosodic words may define units of slow speech.
} 
vowels are otherwise unattested word-finally in English. In the second case, [ən], a truly vowel-initial syllable is posited, though vowel-initial words are typically preceded by glottal stop. In these cases, speakers show variability in where they place the syllable boundary: some place it before [m]; some place it after [m]; and some split the [m] in two, allowing it to close the first syllable and open the second. This last case involves fission of a single segment into two, a process which I will now motivate for Yurok. ${ }^{24}$

Following Steriade (1999b), native-speaker syllabification judgments are viewed as the result of word-based syllabification schemas like those shown in (25).

(25) Word-based syllabification (defaults; may be overridden by other phonotactic constraints)

(25a) If $\mathrm{C}_{0}$ is possible word-initially, then $\mathrm{C}_{0}$ is possible syllable-initially.

(25b) If $\mathrm{C}_{0}$ is not possible word-initially, then $\mathrm{C}_{0}$ is not possible syllableinitially.

(25c) If $\mathrm{C}_{0}$ is possible word-finally, then $\mathrm{C}_{0}$ is possible syllable-finally.

(25d) If $\mathrm{C}_{0}$ is not possible word-finally, then $\mathrm{C}_{0}$ is not possible syllablefinally.

(25e) If $\mathrm{V}_{\mathrm{q}}$ is possible word-initially, then $\mathrm{V}_{\mathrm{q}}$ is possible syllable-initially.

(25f) If $\mathrm{V}_{\mathrm{q}}$ is not possible word-initially, then $\mathrm{V}_{\mathrm{q}}$ is not possible syllableinitially.

(25g) If $\mathrm{V}_{\mathrm{q}}$ is possible word-finally, then $\mathrm{V}_{\mathrm{q}}$ is possible syllable-finally.

(25h) If $\mathrm{V}_{\mathrm{q}}$ is not possible word-finally, then $\mathrm{V}_{\mathrm{q}}$ is not possible syllablefinally.

In Yurok, the schema in (25) will determine syllabifications like those shown in $(20 a)$ and $(20 b)$ without further stipulation. For medial clusters like $t m$ and $t m(20 c)$ which occur word-initially, an additional constraint must be introduced incorporating a preference for C over CC onsets. ${ }^{25}$

Now consider how the schemas in (25) will treat intervocalic preglottalized sonorants. Recall from the discussion above that preglottalized sonorants are neutralized to plain sonorants word-initially ( $3 a$ and $4 a$ ). Since a

\footnotetext{
${ }^{24}$ For in-depth studies of English syllabification, including words like lemon, see Treiman $(1983 ; 1986 ; 1988)$ and Treiman and Danis (1988). Fission is also found under expletive infixation for some English speakers: compare mys-fuckin'-sterious, with fission, to Tas-fuckin'mania, without (Pritchett 1984). Since the expletive must be preceded by a heavy syllable, we expect a syllable break between /s/ and /t/ of mysterious. What appears to trigger fission is the fact that /t/ is unaspirated in this word, since it is not syllable-initial. Since English words cannot begin with unaspirated /t/, fission occurs. See Steriade (1999b) for further discussion.

${ }^{25}$ Such a constraint may also be word-based. In this case, the preference for simple C onsets may reflect word-based frequency effects: the majority of words in Yurok begin with CV, not $\mathrm{CCV}$, sequences.
} 
preglottalized sonorant is not possible word-initially, it will not be possible syllable-initially by $(25 b)$. However, in intervocalic position, an alternative syllabification with the glottalized sonorant as coda leaves a following vowel-initial syllable. This syllabification is at odds with (25f): since vowelinitial words do not occur in Yurok, vowel-initial syllables are excluded. Just in case these two syllabifications are ruled out, fission of preglottalized sonorants into glottal stop + plain sonorant occurs. Notice that in this case, no aspect of Yurok word phonotactics is violated: glottal stop is a wellformed word-final segment, and sonorants are well-formed word-initial segments. In addition, there is no incompatibility between syllabification and surface phonetics: the phonetic realization of preglottalized sonorants allows them to be interpreted phonologically as either single segments or clusters. In (26), the analysis is illustrated for preglottalized sonorants in intervocalic, preconsonantal, and word-final positions.

(26) Yurok word-based syllabification

Actual Illicit

syllabification syllabification

(26a) ke'.win (21)

*ke.'win

*ke'w.in

(26b) ho'y.k'e.tek' (3B)
Word phonotactics (25)/notes

Conforms to (25) with segmental fission

Preglottalized sonorants are not possible word-initially, therefore, preglottalized sonorants are not possible syllable-initially (25b)

Vowels are not possible wordinitially, therefore, vowels are not possible syllableinitially $(25 f)$

Conforms to (25) without fission

The cluster [yk'] is not possible word-initially, therefore, it is not possible syllable-initially $(25 b)$

*ho.'yk'e.tek' The cluster ['yk'] is not possible word-initially, therefore, it is not possible syllable-initially $(25 b)$ 

fission.

The regularity of fission appears to follow directly from the statements in (25). Consider first the case of intervocalic preglottalized sonorants, as exemplified by the form in (26a). Syllabifications like ke.'win violate (25b), since glottalized sonorants are not tolerated word-initially. However, the alternative, $k e$ 'w.in, violates $(25 f)$, since words cannot begin with vowels in Yurok. In this case, segmental fission occurs to satisfy the constraints in (25). The analysis in (26a) accounts for regular fission in all the examples in (21) and in similar words where a preglottalized sonorant is intervocalic. ${ }^{26}$ The form in (26b) is representative of cases where glottalized sonorants are preconsonantal. In this context, they are consistently syllabified as coda segments, since Yurok does not allow word-initial sonorant-obstruent clusters. The form in (26c) is representative of all words which end in glottalized sonorants. Since word-based patterns are the basis for word-internal syllabifications in (25), fission is generally unexpected at word edges. The analysis proposed for Yurok which makes use of the word-based syllabification schema in (25) does not require any special statements regarding word-medial vs. word-final syllabification of segments. Fission of preglottalized sonorants occurs only when its absence would give rise to violations of (25). ${ }^{27}$

An obvious question is why regular fission, such as that found in Yurok, is not common in the world's languages. I suggest that the rarity of regular fission stems from the range of preconditions which must be met for it to occur. These are listed in (27).

(27) Proposed preconditions for segmental fission

I. Phonotactic

A. Word-medial segments which cannot be syllabified in accordance with (25) but which ARE well-formed under segmental fission.

\footnotetext{
${ }^{26}$ A reviewer asked why the output of fission is not a sonorant $+?$ cluster. I assume that the ordering of glottal closure within glottalized segments is specified within the grammar. In representational terms, glottalization in sonorants is aligned with the closure portion of the segment as opposed to the release. These timing properties are maintained under fission, despite the apparent destruction of segmental integrity.

${ }^{27}$ A reviewer suggested that fission could be derived from universal constraints like Onset and a constraint requiring that preglottalized sonorants be postvocalic. The proposed constraints are undominated in Yurok but violable in other languages. However in V'RV strings, the preglottalized sonorant Is postvocalic. A syllabification like V.'RV does not alter adjacency relations within the segmental string. Under any analysis, an intermediate level of analysis is necessary where the surface constraint prohibiting preglottalized segments word-initially is interpreted as syllabic constraint, along the lines of (25).
} 


\section{Phonological}

$B$. Productive phonological processes must take syllabified forms as input; otherwise there is no intrinsic necessity for strings to be exhaustively syllabified at the level of phonological representation.

III. Phonetic

$C$. The output of segmental fission must be simultaneously interpretable as a well-formed cluster in the language and as a well-formed single segment.

6. Summary. Yurok preglottalized sonorants present an interesting problem for general phonological theory. Regular processes of the language, including truncation, laryngeal neutralization, and conditioned vowel lowering, require a single-segment analysis, while syllabifications based on both nativespeaker judgments and stress patterns suggest they are bisegmental sequences. The solution I propose allows segmental fission, just in case fission is the only consistent means for arriving at well-formed syllabifications. I have also suggested in (27) that fission will be evident only in languages in which exhaustive syllabification is necessary for the determination of other sound patterns like stress or syncope, and that phonetic conditions may be relevant as well.

The Yurok data are important not only for our understanding of segmental fission, and the conditions under which it may occur, but also for larger questions regarding the precise nature of syllabification. In this context, the sound patterns of Yurok glottalized sonorants add to growing evidence that syllabifications which serve as input to phonological processes are determined by surface word-based schemas like those in (25). Native-speaker judgments are consistent when all statements in (25) are satisfied; in other cases, inconsistency is evident. Under this account, word-edge phonotactics provide the basis for word-internal syllabification judgments. Statements like those in (25) may constitute part of a universal account of syllabification, but the patterns on which they are based may be highly language-specific.

\section{REFERENCES}

ARChangeli, Diana. 1983. The root CV template as property of the affix: evidence from Yawelmani. Natural Language and Linguistic Theory 1:347-84. . 1984. Underspecification in Yawelmani phonology and morphology. Ph.D. dissertation, Massachusetts Institute of Technology. [Published New York: Garland Press, 1988.]

Berman, Howard. 1982a. A supplement to Robins's Yurok-English lexicon. IJAL 48:197-241. . 1982b. Two phonological innovations in Ritwan. IJAL 48:412-20.

BLEVINS, JuLIETTE. 1993. Klamath laryngeal phonology. IJAL 59:237-79. 1995. The syllable in phonological theory. Handbook of Phonological Theory, ed.

John Goldsmith, pp. 206-44. London: Basil Blackwell. 
2002a. The independent nature of phonotactic constraints: an alternative to syllablebased approaches. The Syllable in Optimality Theory, ed. Caroline Féry and Ruben van de Vijver, pp. 375-403. Cambridge: Cambridge University Press.

$2002 b$. Notes on sources of Yurok glottalized consonants. Proceedings of the Meeting of the Hokan-Penutian Workshop, ed. L. Hinton and L. Buszard-Welcher, Survey of California and Other Indian Languages, Report 11:1-18.

2002c. Prosodic words in Yurok. Paper presented at the SSILA Winter Meeting, San Francisco.

2003a. Yurok syllable weight. IJAL 69:4-24.

$2003 \mathrm{~b}$. One case of contrast evolution in the Yurok vowel system. IJAL 69:135-50.

Blevins, Juliette, And Andrew Garrett. 1998. The origins of consonant-vowel metathesis. Language 74:508-56.

. Forthcoming. The evolution of metathesis. The Phonetic Basis of Phonology, ed. Bruce Hayes, Robert Kirchner, and Donca Steriade. Cambridge: Cambridge University Press.

Breen, Gavan, and Rob Pensalfini. 1999. Arrernte: a language with no syllable onsets. Linguistic Inquiry 30:1-25.

Buckley, Eugene. 1994. Theoretical Aspects of Kashaya Phonology and Morphology. Stanford, Calif.: CSLI Publications.

Exline, Jessie. n.d. Yurok Dictionary. [Eureka, Calif.]: Yurok Tribe.

Goddard, Ives. 1990. Algonquian linguistic change and reconstruction. Linguistic Change and Reconstruction Methodology, ed. Philip Baldi, pp. 99-114. Berlin: Mouton de Gruyter.

Gordon, Matthew, and Peter Ladefoged. 2001. Phonation types: a cross-linguistic overview. Journal of Phonetics 29:383-406.

HARRIS, JOHN. 1999. Release the captive coda: the foot as a domain of phonetic interpretation. UCLA Working Papers in Linguistics 11:165-94. [To appear in Papers in Laboratory Phonology 6.]

Howe, Darin, And Douglas Pulleyblank. 2001. Patterns and timing of glottalization. Phonology 18:45-80.

INONG, KAY. 2002. Yurok Language Lessons. Klamath: The Yurok Tribe.

Kroeber, A. L. 1911. The Languages of California North of San Francisco. University of California Publications in American Archaeology and Ethnology 9.

Kuipers, Aert. 1974. The Shuswap Language. The Hague: Mouton.

Newman, Stanley. 1944. Yokuts Language of California. Viking Fund Publications in Anthropology, vol. 2. New York: Viking Fund.

Nichols, JohanNA. 1971. Diminutive consonant symbolism in Western North America. Language 62:56-119.

PritchetT, BRAD. 1984. The Mys-fuckin-sterious behavior of s-stop clusters in English expletive infixation. Ms., Harvard University.

RobIns, R. H. 1958. The Yurok Language: Grammar, Texts, Lexicon. UCPL 15. Berkeley: University of California Press.

SAPIR, EDWARD. 1911. Diminutive and augmentative consonantism in Wishram. The Handbook of American Indian Languages, pt. 1, ed. Franz Boas, Bulletin of the Bureau of American Ethnology 40:638-45.

. 1933. La réalité psychologique des phonemes. Journal de Psychologie Normale et Pathologique 30:247-65.

2001. Yurok texts, edited by Howard Berman. Collected Work of Edward Sapir, vol. 14, Northwest California Linguistics, ed. Victor K. Golla and Sean O’Neill. Berlin: Mouton de Gruyter.

Sommer, Bruce. 1969. Kunjen Phonology: Synchronic and Diachronic. Pacific Linguistics B-11. Canberra: Australian National University. 
. 1970. An Australian language without CV syllables. IJAL 36:57-58.

Spott, Robert, And A. L. Kroeber. 1942. Yurok narratives. University of California Publications in American Archaeology and Ethnology 35:143-256.

Steriade, DonCA. 1999a. Phonetics in phonology: the case of laryngeal neutralization. Papers in Phonology 3, UCLA Working Papers in Linguistics 2, ed. Matthew Gordon, pp. 25-147. Los Angeles: Department of Linguistics, University of California.

. 1999b. Alternatives to the syllabic interpretation of consonantal phonotactics. Proceedings of the 1998 Linguistics and Phonetics Conference, ed. O. Fujimura, B. Joseph, and B. Palek, pp. 205-42. Prague: The Karolinum Press.

Thompson, LuCy. 1991 [1916]. To the American Indian. Berkeley, Calif.: Heyday Books.

Treiman, Rebecca. 1983. The structure of spoken syllables: evidence from novel word games. Cognition 15:49-74.

. 1986. The division between onsets and rimes in English syllables. Journal of Memory and Language 25:476-91.

1988. Distributional constraints and syllable structure in English. Journal of Phonetics 16:221-29.

Treiman, RebeCCA, AND C. DANIs. 1988. Syllabification of intervocalic consonants. Journal of Memory and Language 27:87-104.

Trull, Georgiana. 2001. Yurok language camp notes, typed by Kay Inong. Ms., Yurok Tribe.

Waterman, T. T. 1920. Yurok geography. University of California Publications in American Archaeology and Ethnology 16:177-314. 